\title{
Five-Year, Disease-Free Survival after Repeat Palliative Multimodality Therapy in a Patient with Recurrent Metastastic Bladder Cancer
}

\author{
Sebastian Fetscher ${ }^{1^{*}}$, Jan Schmielau ${ }^{1}$, and Wolfgang Schulze-Seemann ${ }^{2}$ \\ ${ }^{1}$ Division of Hematology and Oncology, Department of Internal Medicine, Sana \\ Hospital Lübeck, Kronsforder Allee 72-74, D-23560 Lübeck, Germany; ${ }^{2}$ Department \\ of Urology, Freiburg University Hospital Medical Centre, Hugstetter Strasse 55, D- \\ 79106 Freiburg im Breisgau, Germany \\ E-mail: S.Fetscher@sana-luebeck.de
}

Received September 11, 2007; Revised October 3, 2007; Accepted October 11, 2007; Published October 22, 2007

In appropriately selected cases, palliative therapeutic strategies can be adapted to those special features of cancer biographies that indicate an atypical course of disease. Elucidating these features, and adapting multimodal treatment strategies to them, can lead to significantly superior effects when compared to the routine application of conventional treatment algorhythms. A case of regionally metastactic bladder cancer is presented that documents the value of repeat debulking-surgery and repeat radiotherapy leading to unexpected short-term and long-term treatment results.

KEYWORDS: bladder cancer, lymph-node metastasis, palliative surgery, palliative radiotherapy, regionally metastatic bladder cancer

\section{INTRODUCTION}

Urothelial cancer of the bladder (UCB) is one of the most common and lethal human malignancies affecting more than 250,000 patients annually, about half of which will succumb to the disease. Median survival of untreated patients with locally inoperable or metastatic disease averaged 3-6 months in historical series. While palliative chemotherapy can improve median survival to 8-12 months, long-term survival remains exceptional[45].

\section{NODE-NEGATIVE BLADDER CANCER}

UCB is regarded as curable only when confined to the bladder[24,32,35]. However, even in patients with locally confined, node-negative bladder cancer treated with radical cystectomy, cure rates vary considerably depending on tumor stage, size, histological classification, and other molecular risk factors[7,24,32,35]. 


\section{BLADDER CANCER WITH PELVIC LYMPH NODE INVOLVEMENT}

Patients with node-positive UCB have a worse outcome than those with node-negative disease. Whether these patients should be treated with radical cystectomy and extended bilateral lymphadenectomy or without surgery remains subject to debate; locoregional radiotherapy with chemotherapy has been considered an alternative to surgery in node-positive disease[8,11,12,13,14,15,21,29,36]. Regardless of treatment chosen, however, long-term cure is attained only by a small minority of node-positive patients[7,8]. For example, median survival for patients with more or less than five positive nodes after complete tumor resection was 15 and 27 months, respectively, in a Swiss study[7,21].

The following factors have been shown to influence disease-free and overall survival in patients with node-positive UCB: T- and N-stage, density (defined as ratio of positive nodes to total number of nodes examined) and extent of nodal disease (defined by cut-offs at $<5,6-7$, and $>8$ affected nodes), extracapsular carcinomatous extension, and organ-confined or nonorgan-confined primary tumors[7,12,14,21,35,36,42].

The number of lymph nodes resected in UCB reflects the radicality of the surgical approach, physiological variation in nodal anatomy, and differences in the diligence of pathology examination. As in other solid tumors, such as breast or colon cancer, the number of resected nodes has been shown to have an impact on survival even in node-negative tumors[14,36]. In node-positive disease, however, a statistically significant relationship between number of lymph nodes examined and survival could not be confirmed by most investigators[12,14,36,37].

The recommended number of pelvic lymph nodes to be resected with radical cystectomy and extended bilateral lymphadenectomy is said to be between 20 and 25[7]. For patients with five or fewer positive nodes, a survival benefit was demonstrated when a minimum of 16 nodes was resected in total[14]. Reduction in the number of pelvic nodes resected at the time of primary operation in locally advanced urothelial cancer of the bladder (UTCA) resulted in inferior staging and inferior relapse-free survival in a recent study[4a]. These observations indicate that lymphadenectomy in UCB is not merely a staging procedure, but may have a therapeutic and prognostic role in selected populations[5a,7,12a].

\section{BLADDER CANCER WITH EXTRAPELVIC, INTRA-ABDOMINAL NODAL INVOLVEMENT}

Radical cystectomy with bilateral pelvic lymphadenectomy can have a curative role in selected patients with pelvic lymph node disease; in particular, postchemotherapy surgery has been shown to result in longterm, disease-free survival in some patients when adequate measures to select surgical candidates after response to palliative chemotherapy were taken[5a,12a].

The question, whether patients with extrapelvic nodal disease - in the absence of visceral or other metastases - may benefit from surgical and other treatment modalities has not been addressed. Median survival of patients with untreated extrapelvic nodal disease has been reported at 6 months[45]. With the use of palliative chemotherapy or radiotherapy, median survivals of up to 12 months have been described[45].

Chemotherapy with methotrexate, vinblastine, adriamycin and cis-platinum (MVAC) or gemcitabine plus cis-platinum (GC) in patients with locally advanced and metastastic UCB resulted in a 5-year overall survival of 6.8 and $20.9 \%$ for patients without or with visceral metastasis, respectively[48]. However, a third of the patients in this study did not have metastatic disease (defined as M1 by Union International Contre Cancer (UICC) criteria), so that the survival of patients with M1-stage by virtue of extraregional lymph node metastasis probably is worse than these figures. 


\section{BLADDER CANCER METASTATIC TO EXTRANODAL SITES}

Overall median survival for patients treated with GC is 12-14 months; estimated 4-year survivals range from 5-15\%. Results for patients treated with MVAC are comparable. Karnofsky performance score (KPS), presence or absence of visceral metastases, elevated serum alkaline phosphatase, as well as the number of disease sites (>3 vs. $\leq 3$ ) have been described as prognostic variables[13,14,15].

A Swiss group recently reported a cumulative 17\% 5-year survival rate from MVAC studies. Pretreatment prognostic factors significantly affect survival. Patients with a poor KPS and evidence of visceral disease did not experience long-term survival, in contrast to a 33\% likelihood of 5-year survival in patients with none of these features[7,21].

\section{CASE REPORT}

In April 1998, a 61-year-old patient experienced relapsing urinary tract infections. Infections were treated. No structural abnormalities of the urinary tract were identified, however, atypical cells were observed in urine cytology. Follow-up cytologies from 1998 to 2001 displayed an increasing extent of atypical and dysplastic cells. In July 2001, cystoscopy revealed a small superficial bladder malignancy. Repeat cytoscopies led to the discovery of relapse lesions, leading to repeat transurethral resections between July and November 2001. Tumor stage progressed from pTis, pTa, pT1, to pT2, while grade progressed from GIIb to GIII during this time.

In December 2001, repeat cystoscopy documented muscle-invasive carcinoma. While abdominal computed tomography (CT) did not reveal extravesical disease, magnetic resonance investigation (MRI) of the pelvis revealed left iliac, right inguinal, and retroperitoneal lymph node enlargement. After discussion of the therapeutic options with the patient, the decision to perform a radical cystoprostatovesiculectomy with bladder reconstruction using an ileum conduit was made. Intraoperatively, lymph node metastases as demonstrated by MRI were detected and resected by radical bilateral pelvic lymphadenectomy; included were the following nodal compartments: iliaca interna, iliaca externa, obturatoria; limit of initial nodal resection was the aortic bifurcation. However, when surgical inspection documented extension of lymph node spread to the left para-aortic region not visualized by MRI, lymphadenectomy was extended to this area; resection was limited to $1 \mathrm{in}$. above the inferior mesenteric artery. Postoperative tumor stage was pT3b, pN2 (07/14), pM1 (extraregional lymph nodes; 5/8 nodes positive), G3, R0.

In January 2002, adjuvant chemotherapy with cis-platinum and gemcitabine was given. However, due to severe side effects, treatment was terminated after a single infusion of these agents. Therapy with cisplatinum resulted in extensive intraperitoneal fluid accumulation, presumably by leakage through the neobladder. The resulting aseptic peritonitis with subileus was treated with intensive medical management. After recuperation from this WHO IV complication, gemcitabine was given, however, after the infusion WHO II, capillary leak syndrome ensued[4]. Lastly, third-line adjunct chemotherapy using a combination of carboplatinum and vinblastine resulted in the rapid development of WHO II peripheral neuropathy. Based on these negative experiences, no further chemotherapy was given to the patient since.

In July 2003, CT showed enlarged lymph nodes in the para-aortic space. At the time of this, and of each subsequent relapse until 2007, the patient was asymptomatic. Salvage lymphadenectomy demonstrated metastatic involvement in 12 of 21 nodes. In view of negative prior experience with chemotherapy, external beam radiation therapy (37.8 Gray) was given as adjunct to surgery.

In March 2004, CT and positron emission tomography (PET) revealed left para-aortic and left cervical node enlargement. Needle biopsy of the cervical node demonstrated cells compatible with urothelial carcinoma. With metastatic disease above the diaphragm, radiation therapy was chosen as palliative. Treatment was performed in Brussels using the NOVALIS technique, which applies stereotactic planning and application of external beam-focused radiation analogous to intracranial stereotactic approaches. 30 Gray were applied to left cervical and para-aortic region. 
In May 2005, CT and PET results again indicated para-aortic disease. A second salvage lymphadenctomy demonstrated 6 of 14 nodes to be affected; for the first time, the procedure was classified as R1 resection in two areas. Surgical exposure included the entire length on the aorta below the diaphragm, including the pararenal space. Extensive carcinomatous plaques tightly adherent to the aortic wall were resected; this manifestation had not been detected by CT or PET. Again, adjunct radiotherapy (39.6 Gray) was performed using the above-mentioned NOVALIS technique.

As of March 2007, 5 years and 3 months after the diagnosis of a pT3b, pN2, pM1, G3 UCB, signs or symptoms of persistent or recurrent disease were absent. The patient works full time as an academic teacher and president of an international postgraduate institution. He has missed an average of 2 weeks of work per year since 2001. His quality of life has been affected only with regards to altered urogential function. No other significant therapy-related side effects have occurred. In particular, despite the cumulative resection of 57 retroperitoneal lymph nodes during three lymphadenectomies, secondary lymphedema of the lower extremities has not been observed.

Since the patient's treatment history began at the age of 64 and included four transurethral resections, three extensive abdominal operations, two chemotherapies, and three full-dose courses of radiation therapy, the absence of debilitating treatment sequelae may be as remarkable in this case as is the diseasefree state as of March 2007 by clincial, CT, and PET criteria 5 years after the initial diagnosis of UCB.

\section{Addendum (October 2007)}

In April 2007, the patient developed symptomatic, right-sided ureteral obstruction necessitating implantation of a double-J cathether. After CT documentation of ureteral tumor invasion, salvage lymphadenctomy \#3 was performed demonstrating metastatic disease in 7 of 14 resected lymph nodes and in retroperitoneal soft tissue; for the first time, the procedure had to be classified as R2 resection. Ureteral obstruction was relieved, the stent could be removed, no symptoms remained.

Based on these intraoperative findings, a gene-expression analysis of the tumor tissue (Onctest Company, Freiburg, Germany; chief investigator, H.H. Fiebig) was performed and resulted in the recommendation to apply systemic therapy with bevacizumab and docetaxel. After 4 cycles of this therapy, a partial remission of residual intra-abdominal disease was observed. Chemotherapy and antiangiogenetic therapy are planned to continue for another 2 months. Afterwards, maintenance treatment with bevacizumab is envisioned.

\section{DISCUSSION}

The case history reported here contains a number of unusual features that deserve discussion. To begin with, the sequence of treatments chosen for this patient reflect an unusual constellation of elements.

- An unusual pattern of regionally metastastic and relapsing UCB, restricted to nodal disease during a period of more than 5 years

- Relapsing retroperitoneal nodal metastases unusually amenable repeated surgical resection

- Residual disease after each operation apparently sensitive to adjunct radiation therapy

- A patient with an unusually high tolerance for repeated surgical and radiation therapies

- A patient with a particular intolerance to chemotherapy, preventing the application of adequate chemotherapy or chemoradiotherapy prior to or after the surgical procedures

- A urological surgeon able to perform four sequential abdominal lymphadenectomies with the initial cystoprostatovesiculectomy, as well as 19, 41, and 64 months later without significant sequelae 
- A radiotherapy institution performing a palliative primary radiation for first nodal relapse 19 months after initial therapy and another institution using a different technique for palliative radiation of nodal relapses 27 and 41 months after initial diagnosis

- A medical oncologist involved as consultant in each of the above decisions, in particular, in the decision to reoperate nodal relapse.

Given these factors, the clinical observations made in this case cannot be simply translated to the management of other patients with UCB. Nevertheless, the following reflections may deserve attention:

- The case demonstrates that poor-risk patients with regionally metastastic UCB can repeatedly achieve disease control with multimodal therapy despite repeated relapse. This message is all the more important since the patient received pessimistic conventional recommendations all along his patient career. At the initial diagnosis of muscle-invasive UCB, palliative radiochemotherapy was recommended. Since the true extent of nodal metastastic disease was only discovered by primary extensive surgery, this treatment was bound to fail predictably since a part of the lymph nodes involved would have been outside the conventional radiation field.

- The patient's poor tolerance of chemotherapy likely would have made the implementation of an effective radiochemotherapy impossible, at least in the postoperative setting. At each of the relapses, standard recommendation had been palliative chemotherapy using GC or MVAC. Neither repeat surgery, nor repeat radiotherapy was considered a useful option. If these treatment options had been forfeited, as was strongly recommended, disease control as documented here would hardly have been achieved.

- The only alternative for this case suggested by the literature would have been to institute neoadjuvant chemotherapy or chemoradiotherapy in order to improve the results of secondary surgical resection[5a,12a]. The curative potential represented by the favorable results published in the operable, chemosensitive subset of patients with locally advanced or regionally metastastic bladder cancer by Dodd and Herr is, however, by no means universally appreciated by the urological community. The case presented here documents another route to achieve disease control in regionally metastatic bladder cancer: the sequential implementation of lymphadenectomy and postsurgical radiotherapy.

In sum, the case history documented here supports the conclusion that by adapting palliative therapeutic strategies to unique cancer biographies, treatment results can be achieved that may be significantly superior to those attained by executing conventional treatment algorithms. With the everincreasing pressure on the medical and oncological community to define and adhere to "treatment standards", individual observations such as the one presented here may serve as a reminder that, in properly selected patients, metastastic bladder cancer can be successfully treated with repeat surgery and adjunct radiotherapy.

\section{REFERENCES}

1. Bajorin, D.F., Dodd, P.M., Mazumdar, M., et al. (1999) Long-term survival in metastatic transitional-cell carcinoma and prognostic factors predicting outcome of therapy. J. Clin.Oncol. 17, 3173-3181.

2. Castellano, D., Lianes, P., Paz-Ares, L., et al. (1998) A phase II study of a novel gemcitabine plus cisplatin regimen administered every three weeks for advanced non-small-cell lung cancer. Ann. Oncol. 9, 457-459.

3. Chan, S., Friedrichs, K., Noel, D., et al. (1999) Prospective randomized trial of docetaxel versus doxorubicin in patients with metastatic breast cancer. J. Clin. Oncol. 17, 2341-2354.

4. De Pas, T., Curigliano, G., Franceschelli, L., Catania, C., Spaggiar, L., and de Braud, F. (2001) Gemcitabine-induced systemic capillary leak syndrome. Ann. Oncol. 12, 1651-1652.

4a. Dhar, N.B., Campbell, S.C., Zippe, C.D., Derweesh, I.H., Reuther, A.M., Fergany, A., and Klein, E.A. (2006) Outcomes in patients with urothelial carcinoma of the bladder with limited pelvic lymph node dissection. BJU Int. 98(6), 1172-1175. 
5. Dodd, P.M., McCaffrey, J.A., Mazumdar, M., et al. (1999) Phase II trial of intermediate-dose methotrexate in combination with vinblastine, doxorubicin, and cisplatin in patients with unresectable or metastatic transitional cell carcinoma. Cancer 85, 1145-1150.

5a. $\quad$ Dodd, P.M., McCaffrey, J.A., Herr, H., et al. (1999) Outcome of postchemotherapy surgery after treatment with methotrexate, vinblastine, doxorubicin, and cisplatin in patients with unresectable or metastastic transitional-cell cancer of the bladder. J. Clin. Oncol. 17(8), 2546-2552.

6. Droz, J.P., Mottet, N., Prapotrich, D., et al. (1998) Phase II study of Taxol (paclitaxel) and carboplatin in patients with advanced transitional-cell carcinoma of the urothelium: preliminary results. Proc. Am. Soc. Clin. Oncol. 17, 316a.

7. Fleischmann, A., Thalmann, G.N., Markwalder, R., and Studer, U.E. (2005) Extracapsular extension of pelvic lymph node metastases from urothelial carcinoma of the bladder is an independent prognostic factor. J. Clin. Oncol. 23(10), 2358-2365.

8. Galsky, M.D. and Scheer, H.I. (2005) Bladder cancer “aduvant lite”: tastes great (works as well) and less filling (less toxic)? J. Clin. Oncol. 23(22), 4823-4826.

9. Gabrilove, J.L., Jakubowski, A., Scher, H., et al. (1988) Effect of granulocyte colony-stimulating factor on neutropenia and associated morbidity due to chemotherapy for transitional-cell carcinoma of the urothelium. N. Engl. J. Med. 318, 1414-1422.

10. Geller, N.L., Sternberg, C.N., Penenberg, D., et al. (1991) Prognostic factors for survival of patients with advanced urothelial tumors treated with methotrexate, vinblastine, doxorubicin, and cisplatin chemotherapy. Cancer 67, 15251531.

11. Griebling, T.L., Ozkutlu, D., See, W.A., et al. (1997) Prognostic implications of extracapsular extension of lymph node metastases in prostate cancer. Mod. Pathol. 10, 804-809.

12. Herr, H.W., Bochner, B.H., Dalbagni, G., et al. (2002) Impact of the number of lymph nodes retrieved on outcome in patients with muscle invasive bladder cancer. J. Urol. 167, 1295-1298.

12a. Herr, H.W., Donat, S.M., and Barjorin, D.F. (2001) Postchemotherapy surgery in patients with unresectable or regionally metastastic bladder cancer. J. Urol. 165(3), 811-814.

13. Kaufman, D., Raghavan, D., Carducci, M., et al. (2000) Phase II trial of gemcitabine plus cisplatin in patients with metastatic urothelial cancer. J. Clin. Oncol. 18, 1921-1927.

14. Leissner, J., Hohenfellner, R., Thuroff, J.W., et al. (2000) Lymphadenectomy in patients with transitional cell carcinoma of the urinary bladder: significance for staging and prognosis. BJU Int. 85, 817-823.

15. Lerner, S.P., Skinner, D.G., Lieskovsky, G., et al. (1993) The rationale for en bloc pelvic lymph node dissection for bladder cancer patients with nodal metastases: long-term results. J. Urol. 149, 758-764.

16. Loehrer, P.J., Sr., Einhorn, L.H., Elson, P.J., et al. (1992) A randomized comparison of cisplatin alone or in combination with methotrexate, vinblastine, and doxorubicin in patients with metastatic urothelial carcinoma: a cooperative group study. J. Clin. Oncol. 10, 1066-1073.

17. Logothetis, C.J., Dexeus, F.H., Finn, L., et al. (1990) A prospective randomized trial comparing MVAC and CISCA chemotherapy for patients with metastatic urothelial tumors. J. Clin. Oncol. 8, 1050-1055.

18. Lorusso, V., Pollera, C.F., Antimi, M., et al. (1998) A phase II study of gemcitabine in patients with transitional cell carcinoma of the urinary tract previously treated with platinum: Italian Cooperative Group on Bladder Cancer. Eur. J. Cancer 34, 1208-1212.

19. McCaffrey, J.A., Hilton, S., Mazumdar, M., et al. (1997) Phase II trial of docetaxel in patients with advanced or metastatic transitional-cell carcinoma. J. Clin. Oncol. 15, 1853-1857.

20. McCaffrey, J.A., Hilton, S., Mazumdar, M., et al. (1997) Phase II randomized trial of gallium nitrate plus fluorouracil versus methotrexate, vinblastine, doxorubicin, and cisplatin in patients with advanced transitional cell carcinoma. $J$. Clin. Oncol. 15, 2449-2455.

21. Mills, R.D., Turner, W.H., Fleischmann, A., et al. (2001) Pelvic lymph node metastases from bladder cancer: outcome in 83 patients after radical cystectomy and pelvic lymphadenectomy. J. Urol. 166, 19-23.

Moore, M.J., Tannock, I.F., Ernst, D.S., et al. (1997) Gemcitabine: a promising new agent in the treatment of advanced urothelial cancer. J. Clin. Oncol. 15, 3441-3445.

23. Moore, M.J., Winquist, E.W., Murray, N., et al. (1999) Gemcitabine plus cisplatin, an active regimen in advanced urothelial cancer: a phase II trial of the National Cancer Institute of Canada Clinical Trials Group. J. Clin. Oncol. 17, 2876-2881.

24. Parkin, D.M., Pisani, P., and Ferlay, J. (1999) Global cancer statistics. CA Cancer J. Clin. 49, 33-64.

25. Peters, G.J., Bergman, A.M., Ruiz van Haperen, V.W., et al. (1995) Interaction between cisplatin and gemcitabine in vitro and in vivo. Semin. Oncol. 22(Suppl 11), 72-79. Pollera, C.F., Ceribelli, A., Crecco, M., et al. (1994) Weekly gemcitabine in advanced bladder cancer: a preliminary report from a phase I study. Ann. Oncol. 5, 182-184.

27. Redman, B.G., Smith, D.C., Flaherty, L., et al. (1998) Phase II trial of paclitaxel and carboplatin in the treatment of advanced urothelial carcinoma. J. Clin. Oncol. 16, 1844-1848.

28. Robinson, P., von der Maase, H., Bhalla, S., et al. (2004) Cost-utility analysis of the GC versus MVAC regimens for the treatment of locally advanced or metastatic bladder cancer. Expert Rev. Pharmacoeconomics Outcomes Res. 4, 27-38.

29. Roehrborn, C.G., Sagalowsky, A.I., and Peters, P.C. (1991) Long-term patient survival after cystectomy for regional 
metastatic transitional cell carcinoma of the bladder. J. Urol. 146, 36-39.

30. Saxman, S.B., Propert, K.J., Einhorn, L.H., et al. (1997) Long-term follow-up of a phase III intergroup study of cisplatin alone or in combination with methotrexate, vinblastine, and doxorubicin in patients with metastatic urothelial carcinoma: a cooperative group study. J. Clin. Oncol. 15, 2564-2569.

31. Seidman, A.D., Scher, H.I., Gabrilove, J.L., et al. (1993) Dose-intensification of M-VAC with recombinant granulocyte colony-stimulating factor as initial therapy in advanced urothelial cancer. J. Clin. Oncol. 11, 408-414.

32. Seitz, M., Zaak, D., Knüchel-Clarke, R., and Stief, C. (2005) Harnblasentumoren - die neue WHO-Klassifikation 2004. Urologe 44, 1073-1086.

33. Sengelov, L., Kamby, C., and von der Maase, H. (2001) Metastatic urothelial cancer: evaluation of prognostic factors and change in prognosis during the last twenty years. Eur. Urol. 39, 634-642.

34. Stadler, W.M., Kuzel, T., Roth, B., et al. (1997) Phase II study of single-agent gemcitabine in previously untreated patients with metastatic urothelial cancer. J. Clin. Oncol. 15, 3394-3398.

35. Stadler, W.M., Hayden, A., von der Maase, H., et al. (2002) Long-term survival in phase II trials of gemcitabine plus cisplatin for advanced transitional cell cancer. Urol. Oncol. 7, 153-157.

36. Stein, J.P., Lieskovsky, G., Cote, R., et al. (2001) Radical cystectomy in the treatment of invasive bladder cancer: long-term results in 1,054 patients. J. Clin. Oncol. 19, 666-675.

37. Stein, J.P., Cai, J., Groshen, S., et al. (2003) Risk factors for patients with pelvic lymph node metastases following radical cystectomy with en bloc pelvic lymphadenectomy: concept of lymph node density. J. Urol. 170, 35-41.

38. Sternberg, C.N., Yagoda, A., Scher, H.I., et al. (1985) Preliminary results of M-VAC (methotrexate, vinblastine, doxorubicin and cisplatin) for transitional cell carcinoma of the urothelium. J. Urol. 133, 403-407.

39. Sternberg, C.N., Yagoda, A., Scher, H.I., et al. (1988) M-VAC (methotrexate, vinblastine, doxorubicin and cisplatin) for advanced transitional cell carcinoma of the urothelium. J. Urol. 139, 461-469.

40. Sternberg, C.N., Yagoda, A., Scher, H.I., et al. (1989) Methotrexate, vinblastine, doxorubicin, and cisplatin for advanced transitional cell carcinoma of the urothelial. Efficacy and patterns of response and relapse. Cancer 64, 2448-2458.

41. Vaughn, D.J., Malkowicz, S.B., Zoltick, B., et al. (1998) Paclitaxel plus carboplatin in advanced carcinoma of the urothelium: an active and tolerable outpatient regimen. J. Clin. Oncol. 16, 255-260.

42. Vieweg, J., Whitmore, W.F., Jr., Herr, H.W., et al. (1994) The role of pelvic lymphadenectomy and radical cystectomy for lymph node positive bladder cancer: the Memorial Sloan-Kettering Cancer Center experience. Cancer 73, 3020-3028.

43. Vieweg, J., Gschwend, J.E., Herr, H.W., et al. (1999) Pelvic lymph node dissection can be curative in patients with node positive bladder cancer. J. Urol. 161, 449-454.

44. von der Maase, H. (2003) Gemcitabine in transitional cell carcinoma of the urothelium. Expert Rev. Anticancer Ther. 3, 11-19.

45. von der Maase, H., Hansen, S.W., Roberts, J.T., et al. (2000) Gemcitabine and cisplatin versus methotrexate, vinblastine, doxorubicin, and cisplatin in advanced or metastatic bladder cancer: results of a large, randomized, multinational, multicenter, phase III study. J. Clin. Oncol. 18, 3068-3077.

46. $\quad$ von der Maase, H., Andersen, L., Crino, L., et al. (1999) Weekly gemcitabine and cisplatin combination therapy in patients with transitional cell carcinoma of the urothelium: a phase II clinical trial. Ann. Oncol. 10, 1461-1465.

47. von der Maase, H.and Sengelov, L. (2005) Chemotherapy in locally advanced and metastatic bladder cancer. Am. J. Cancer 4, 1-13.

48. von der Maase, H., Sengelov, L., Roberts, J.T., et al. (2005) Long-term survival of a randomized trial comparing gemcitabine plus cisplatin versus methotrexate, vinblastine, doxorubicin, and cisplatin in patients with bladder cancer. J. Clin. Oncol. 23, 4602-4608.

49. Witte, R.S., Elson, P., Bono, B., et al. (1997) Eastern Cooperative Oncology Group phase II trial of ifosfamide in the treatment of previously treated advanced urothelial carcinoma. J. Clin. Oncol. 15, 589-593.

\section{This article should be cited as follows:}

Fetscher, S., Schmielau, J., and Schulze-Seemann, W. (2007) Five-year, disease-free survival after repeat palliative multimodality therapy in a patient with recurrent metastastic bladder cancer. TheScientificWorldJOURNAL: TSW Urology 7, 1736-1742. DOI 10.1100/tsw.2007.283. 


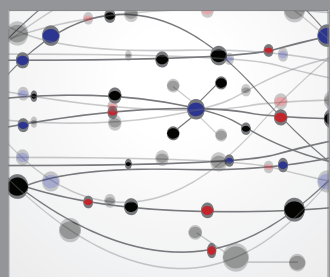

The Scientific World Journal
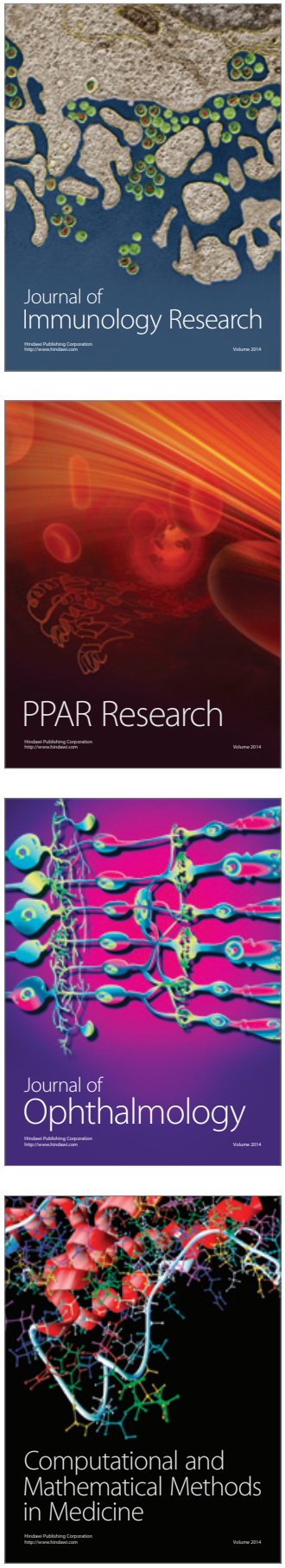

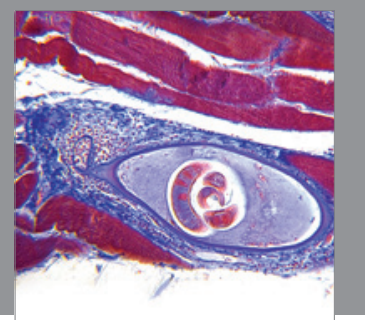

Gastroenterology

Research and Practice
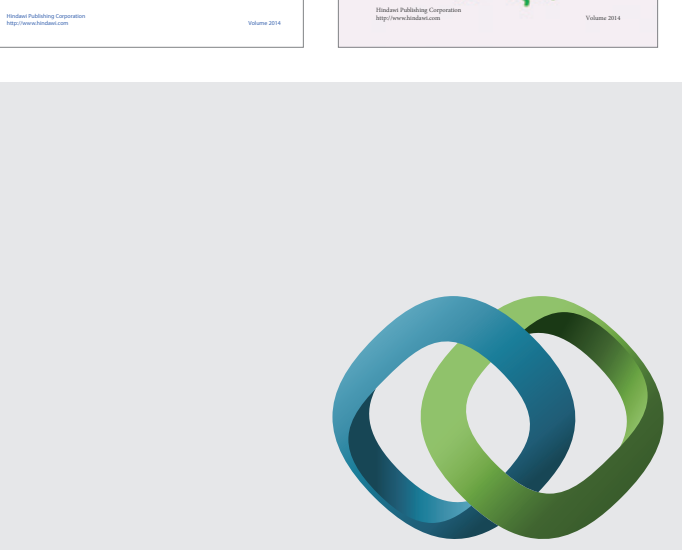

\section{Hindawi}

Submit your manuscripts at

http://www.hindawi.com
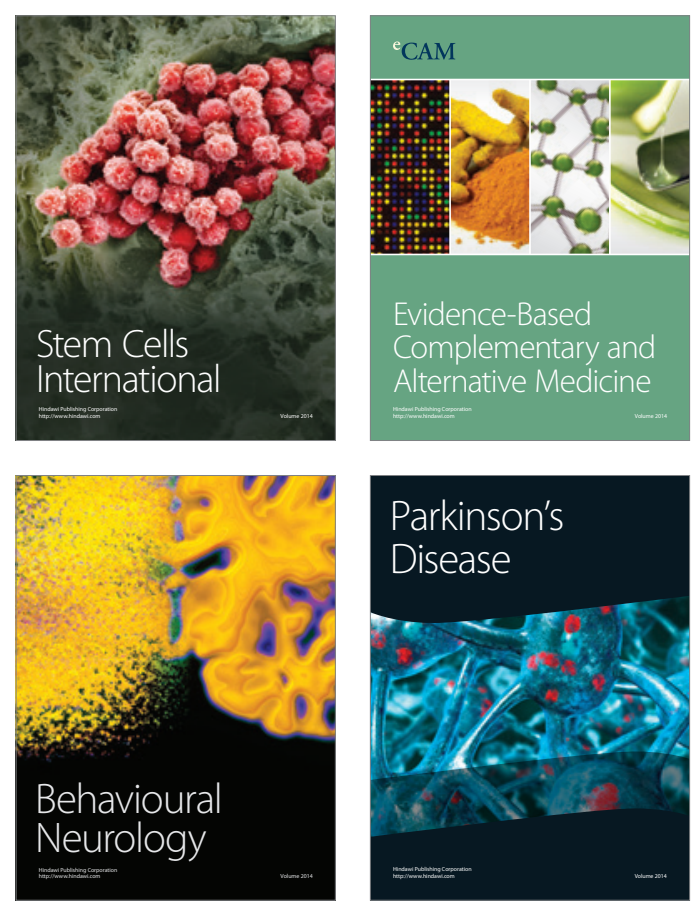

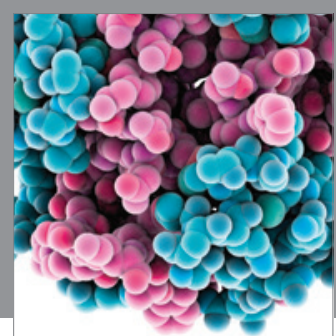

Journal of
Diabetes Research

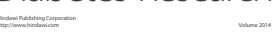

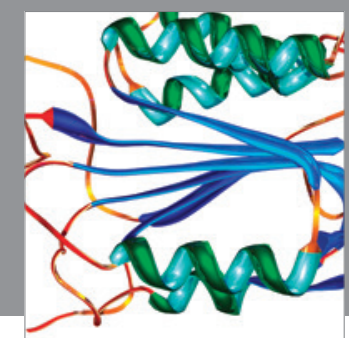

Disease Markers
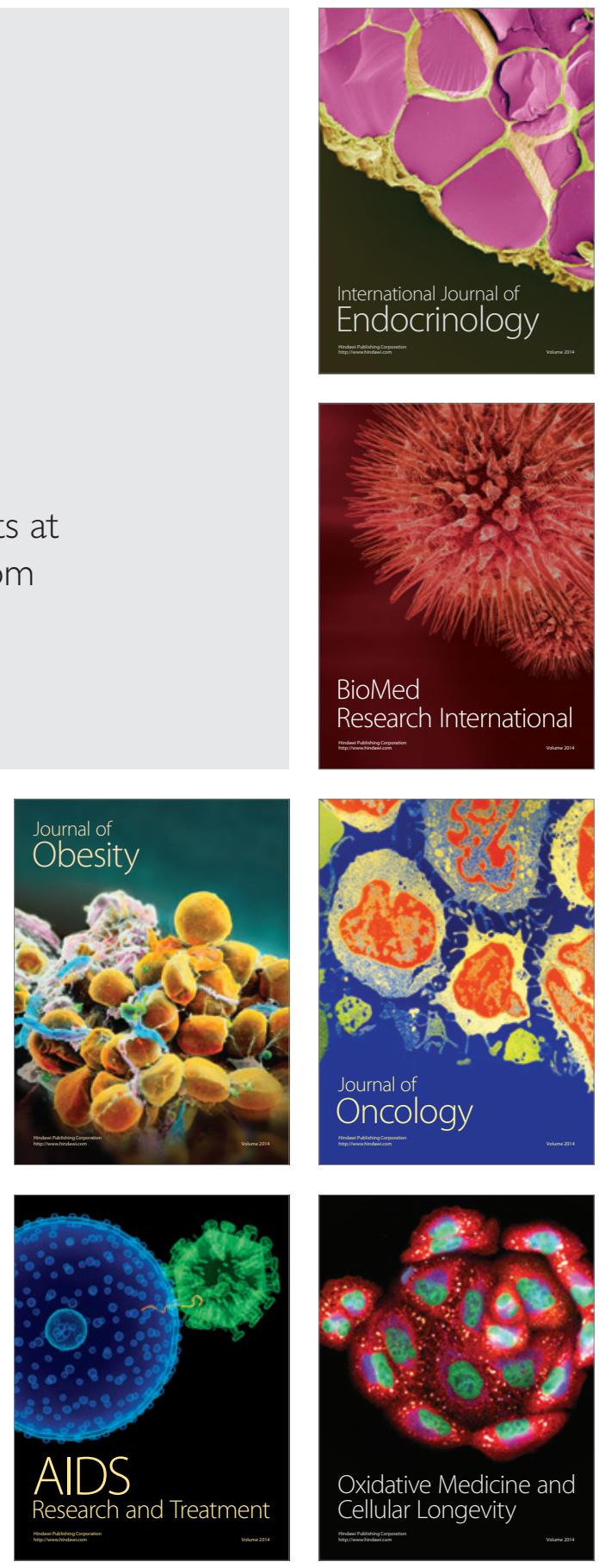